\title{
Removal of Intracellular and Extracellular Antibiotic Resistance Genes from Swine Wastewater by Sequential Electrocoagulation and Electro-Fenton Processes
}

\author{
Lei Chen, ${ }^{1-3,{ }^{*}}$ Shanxue Gao, ${ }^{1}$ Liping Lou, ${ }^{2,4}$ and Zhi Zhou ${ }^{5}$ \\ ${ }^{1}$ Department of Water Science and Engineering, School of Civil Engineering of Nanjing Forestry University, Nanjing, China. \\ ${ }^{2}$ Key Laboratory of Water Pollution Control and Environmental Safety of Zhejiang Province, Hangzhou, China. \\ ${ }^{3}$ Jiangsu Provincial Key Laboratory of Environmental Science and Engineering, Suzhou University of Science and Technology, Suzhou, China. \\ ${ }^{4}$ Department of Environmental Engineering, College of Environmental and Resource Sciences, Zhejiang University, Hangzhou, China. \\ ${ }^{5}$ Division of Environmental and Ecological Engineering and School of Civil Engineering, Purdue University, West Lafayette, Indiana, USA.
}

Received: May 21, 2020 Accepted in revised form: August 9, 2020

\begin{abstract}
Antibiotics are often used excessively in the livestock industry, and the effluent from livestock wastewater treatment is one of the main sources of antibiotic resistance genes (ARGs) in the environment. Biological treatments and traditional disinfection cannot effectively remove ARGs from this wastewater. This study evaluated the feasibility of removing ARGs from actual swine wastewater treatment effluent using single and sequential electrocoagulation (EC) and electro-Fenton (EF) processes. An EC process with 60 min of electrolysis removed the selected intracellular ARGs with a removal efficiency of 2.21-2.83 logs and the extracellular ARGs with a removal efficiency of 1.82-2.56 logs. In comparison, the EF process was less efficient for the removal of intracellular ARGs (1.03-2.19 logs), but more efficient for the removal of extracellular ARGs (3.19-4.02 logs). Compared to the individual EC and EF processes alone, the sequential EC/EF processes were more effective for the removal of both intracellular and extracellular ARGs, with 2.49-3.25 logs and 3.23-4.38 $\operatorname{logs}$ of removal efficiency, respectively. Our results show that the sequential EC/EF treatment might be a promising technology for removing both intracellular and extracellular ARGs from swine wastewater.
\end{abstract}

Keywords: antibiotic resistance genes; electrocoagulation; electro-Fenton; swine wastewater

\section{Introduction}

A NTIBIOTIC RESISTANCE GENES (ARGs) have been identified as emerging pollutants in the environment that reduce the efficacy of antibiotics for infectious diseases, especially in less-developed countries (Goff and Rybak, 2015). This antibiotic resistance can also be disseminated by the sharing of ARGs among microorganisms using a mechanism called horizontal gene transfer (Berendonk et al., 2015). Intracellular ARGs readily adapt to new hosts, and extracellular ARGs, which are released from dead bacterial cells and are often two to three orders of magnitude less abundant than intracellular ARGs, can play an important role in the propagation of ARGs (Dong et al., 2019). The livestock industry is one of the most important economic activities in China, where antibiotics are often excessively used to promote animal growth, as well as to prevent and cure diseases (Zhang et al., 2015a). Animal farms are considered to be important

*Corresponding author: Department of Water Science and Engineering, School of Civil Engineering of Nanjing Forestry University, Longpan Road 159, Nanjing 210037, China. Phone: +86-258542-7691; Fax: +86-25-8697-7226; E-mail: chenlei_njfu@163.com reservoirs of ARGs, and livestock wastewater effluents might be significant sources of the ARGs released into the environment (Auguet et al., 2017). Although disinfection is usually performed after the biological treatment of livestock wastewater, the levels of ARGs in the effluents are still very high, and the discharge and land application of the treated wastewater represent a great threat to the surrounding environment (Jia et al., 2017).

Conventional disinfection processes such as chlorination, ultraviolet (UV) irradiation, and ozone oxidation have been evaluated for the removal of ARGs from wastewater but were determined to be inefficient (Sharma et al., 2016). Usually, a dose of chlorine greater than $30 \mathrm{mg} / \mathrm{L}$, a dose of UV irradiation greater than $10 \mathrm{~mJ} / \mathrm{cm}^{2}$, or a dose greater than $3 \mathrm{mg} / \mathrm{L}$ ozone is required for the effective inactivation of ARGs (Oh et al., 2016; Zheng et al., 2017). However, high doses of disinfectant could simultaneously greatly increase the possibility of ARG transfer (Guo et al., 2015). Advanced oxidation processes such as Fenton oxidation, $\mathrm{TiO}_{2}$ photocatalysis, and $\mathrm{UV} / \mathrm{H}_{2} \mathrm{O}_{2}$ not only showed high removal efficiencies of 2.3-5.8 logs of ARG reduction but also presented a low risk of ARG transfer (Zhang et al., 2016; Guo et al., 2017). Nevertheless, the high energy 
consumption of these processes and the addition of chemical reagents are still problems to be solved.

In the last few years, electrochemical disinfection has received particular attention. As a prospective technology for water and wastewater disinfection, electrochemical disinfection is more eco-friendly and cost-effective than conventional disinfection methods (Ghernaout, 2013). Electrocoagulation (EC) and electro-Fenton (EF) processes are the most promising processes for electrochemical disinfection. During the EC process, coagulants are generated in situ by the electrochemical oxidation of an iron or aluminum anode in an undivided cell, which forms flocs and precipitates with bacteria or contaminants (Ghernaout, 2013). The EC process has been studied for the disinfection of swimming pool water, the removal of organic pollutants, and the disinfection of municipal wastewater and actual swine wastewater (Baran et al., 2018; Rahmani et al., 2019). During the EF process, hydrogen peroxide is continuously electrogenerated in situ, and hydroxyl radical $\bullet \mathrm{OH}$ is produced with the addition of a small amount of iron as a catalyst. As a strong oxidant, $\bullet \mathrm{OH}$ can mineralize most organic compounds and destroy cell structures (Bruguera-Casamada et al., 2017). Compared with the Fenton process, the EF process consumes less energy, produces less waste, and handles $\mathrm{H}_{2} \mathrm{O}_{2}$ more easily (Valero et al., 2017). However, the addition of the iron catalyst is still required. Sequential EC/EF processes without the addition of any chemical reagents have been evaluated for the inactivation of microbiota from urban wastewater (Anfruns-Estrada et al., 2017). Nevertheless, the ability of sequential EC/EF processes to remove ARGs from wastewater, especially from actual livestock farming effluents, has not been explored.

The current study aims to assess the ability of sequential EC/EF processes to remove both intracellular and extracellular ARGs from the effluent of a swine wastewater treatment plant. The frequently detected ARGs in swine wastewater (sul1, sul2, tet $M$, and tet $W$ ) and 16S rRNA, which would reveal the abundance of background bacteria, were selected as the target genes. The results provide a potential alternative technology for the effective removal of ARGs from livestock farming wastewater.

\section{Materials and Methods}

\section{Wastewater sampling}

Wastewater samples were collected from the effluent of a swine wastewater treatment plant on a swine farm in May 2019. The treatment plant uses the anaerobic-anoxic-oxic $\left(\mathrm{A}^{2} \mathrm{O}\right)$ process for the removal of organic matter and nitrogen pollutants. The wastewater had the following characteristics: chemical oxygen demand of $195 \mathrm{mg} / \mathrm{L}$, ammonium nitrogen of $18 \mathrm{mg} / \mathrm{L}$, suspended solids of $152 \mathrm{mg} / \mathrm{L}$, Escherichia coli concentration of $109 \mathrm{CFU} / \mathrm{mL}, \mathrm{pH} \mathrm{7.2,} \mathrm{and} \mathrm{conductivity} \mathrm{of}$ $11.24 \mathrm{mS} / \mathrm{cm}$. The water samples were stored at $4^{\circ} \mathrm{C}$ immediately after collection.

\section{Electrochemical experiments}

All the electrochemical experiments were carried out in an undivided cylindrical glass cell containing $200 \mathrm{~mL}$ of wastewater kept at $25^{\circ} \mathrm{C}$. The reaction solution was stirred with a magnetic bar. A constant current of $20.0 \mathrm{~mA} / \mathrm{cm}^{2}$ was provided by a direct current power supply. For the EC process, the anode and cathode were $10 \mathrm{~cm}^{2} \mathrm{Fe}$ plates and stainless steel (SS) electrodes separated by $1 \mathrm{~cm}$. The Fe surface was mechanically abraded using $\mathrm{SiC}$ paper and cleaned with $0.1 \mathrm{~mol} / \mathrm{L} \mathrm{H}_{2} \mathrm{SO}_{4}$ solution before use. After a specified period of electrolysis, the suspension was left for $2 \mathrm{~h}$ for sedimentation. A sample of $100 \mathrm{~mL}$ was taken from the supernatant for DNA extraction. During the EF treatment, the Pt electrode $\left(5 \mathrm{~cm}^{2}\right)$ was used as the anode, and the SS electrode $\left(10 \mathrm{~cm}^{2}\right)$ was used as the cathode. The $\mathrm{pH}$ of the solution was adjusted to 3.5 with $\mathrm{H}_{2} \mathrm{SO}_{4}$. A small amount of ferrous ions $(1.0 \mathrm{mmol} / \mathrm{L})$ was introduced into the cell. Compressed air was bubbled into the cell continuously at a flow rate of $0.6 \mathrm{~L} / \mathrm{min}$. After a certain period of electrolysis, $100 \mathrm{~mL}$ of the reaction solution was collected for DNA extraction. The sequential EC/EF treatment was composed of an initial EC process with a Fe/SS cell and a subsequent EF process with a Pt/SS cell. The EC process was conducted with electrolysis for $30 \mathrm{~min}$. Then, the supernatant was transferred to another cell with Pt-SS, and the $\mathrm{pH}$ was adjusted to 3.5. The EF treatment was performed for another $30 \mathrm{~min}$, and then a sample of $100 \mathrm{~mL}$ was obtained for DNA extraction. All the electrochemical experiments were performed in triplicate, and three sets of electrochemical devices were in use at the same time. To reduce the effect of water quality on the results, all the electrochemical experiments were carried out within 3 days using the same batches of wastewater.

\section{DNA extraction and real-time quantitative polymerase chain reaction}

Each sample was divided into two parts for intracellular DNA extraction and total DNA extraction (containing both intracellular and extracellular DNA), respectively. The abundance of extracellular ARGs was determined by the difference between the abundance of total ARGs and that of intracellular ARGs. For intracellular DNA extraction, the samples were filtered through $0.22 \mu \mathrm{m}$ membranes (Millipore) for cell interception. For total DNA extraction, sodium acetate (NaAc, $3 \mathrm{~mol} / \mathrm{L}$ ) and absolute ethanol were added to each water sample $\left(\mathrm{V}_{\mathrm{NaAd}} / \mathrm{V}_{\text {Ethanol }} / \mathrm{V}_{\text {Water }}=1: 22: 10\right)$, which was stored at $-20^{\circ} \mathrm{C}$ overnight before centrifugation at $10,000 \mathrm{~g}$ for $10 \mathrm{~min}$ (Zhang et al., 2018). The precipitates were collected and airdried before DNA extraction. The membranes were then stored at $-20^{\circ} \mathrm{C}$ before DNA extraction. Then, a PowerSoil DNA Isolation Kit (MoBio Laboratories) was used to extract the intracellular DNA from the filtered membranes and the total DNA from the precipitates. The concentration and purity of the extracted DNA were determined by a NanoDrop 1000 spectrophotometer (Thermo Scientific). ARGs (sul1, sul2, tetM, and tet $W$ ) and 16S rRNA were quantified using SYBR Green I qPCR on a real-time PCR system. The primers, annealing temperature, and amplification size are provided in Table 1. All the standard curves of the real-time quantitative polymerase chain reaction (qPCR) were prepared from 10-fold serial dilutions of the plasmid-carrying target genes ranging from $10^{8}$ to $10^{2}$ gene copies per microliter (Guo et al., 2017). The qPCR amplification and quantification processes were carried out on a StepOnePlus real-time PCR system (Applied Biosystems). Each reaction was run in triplicate. The $R^{2}$ values for the calibration curve were in the range of $0.991-0.997$. 
Table 1. Primers Used in This Study

\begin{tabular}{|c|c|c|c|c|c|}
\hline Target genes & Primer & Sequence & $\begin{array}{c}\text { Annealing } \\
\text { temperature, }{ }^{\circ} \mathrm{C}\end{array}$ & $\begin{array}{l}\text { Amplicon } \\
\text { size, bp }\end{array}$ & Reference \\
\hline \multirow[t]{2}{*}{ sull } & $\mathrm{F}$ & CACCGGAAACATCGCTGCA & \multirow[t]{2}{*}{57} & \multirow[t]{2}{*}{158} & \multirow[t]{2}{*}{ Li et al. (2017) } \\
\hline & $\mathrm{R}$ & AAGTTCCGCCGCAAGGCT & & & \\
\hline \multirow[t]{2}{*}{ sul2 } & $\mathrm{F}$ & CTCCGATGGAGGCCGGTAT & \multirow[t]{2}{*}{60} & \multirow[t]{2}{*}{190} & \multirow[t]{2}{*}{ Li et al. (2017) } \\
\hline & $\mathrm{R}$ & GGGAATGCCATCTGCCTTGA & & & \\
\hline \multirow[t]{2}{*}{ tetM } & $\mathrm{F}$ & ACAGAAAGCTTATTATATAAC & \multirow[t]{2}{*}{55} & \multirow[t]{2}{*}{171} & \multirow[t]{2}{*}{ Li et al. (2017) } \\
\hline & $\mathrm{R}$ & TGGCGTGTCTATGATGTTCAC & & & \\
\hline \multirow[t]{2}{*}{ tetW } & $\mathrm{F}$ & GAGAGCCTGCTATATGCCAGC & \multirow[t]{2}{*}{64} & \multirow[t]{2}{*}{168} & \multirow[t]{2}{*}{ Sui et al. (2018) } \\
\hline & $\mathrm{R}$ & GGGCGTATCCACAATGTTAAC & & & \\
\hline \multirow[t]{2}{*}{ 16S rRNA } & $\mathrm{F}$ & CCTACGGGAGGCAGCAG & \multirow[t]{2}{*}{65} & \multirow[t]{2}{*}{202} & \multirow[t]{2}{*}{ Zhang et al. (2015b) } \\
\hline & $\mathrm{R}$ & ATTACCGCGGCTGCTGG & & & \\
\hline
\end{tabular}

\section{Statistical analysis}

In this study, removal of ARGs was calculated as the $\log$ removal $\left(\log \mathrm{C} / \mathrm{C}_{0}\right)$, where $\mathrm{C}_{0}$ is the initial abundance of ARGs in the wastewater and $\mathrm{C}$ is the final abundance of ARGs in wastewater after treatment. Pearson correlation analysis was conducted with Statistical Package for the Social Sciences 16.0 for Windows. The difference between pairs of samples was analyzed with a $t$-test and was considered significant at $p<0.05$ for each test.

\section{Results and Discussion}

\section{Concentrations of selected ARGs in untreated wastewater}

The abundance of intracellular ARGs, extracellular ARGs, and 16S rRNA in the untreated wastewater is shown in Table 2. The concentrations of sulfamethoxazole resistance genes (sull and sul2) were higher compared with tetracycline resistance genes (tet $M$ and tet $W$ ). The extracellular ARGs were two to three orders of magnitude less abundant than intracellular ARGs, which is close to the findings by Dong et al. (2019) and Sui et al. (2018).

\section{EC process}

The electrolysis step of the EC process was conducted for $15,30,60$, and $90 \mathrm{~min}$ at neutral $\mathrm{pH}$ and a current density of $20.0 \mathrm{~mA} / \mathrm{cm}^{2}$. As shown in Fig. 1, the removal efficiencies for ARGs and 16S rRNA increased substantially with the electrolysis time. At longer electrolysis periods (more than $60 \mathrm{~min}$ ), the removal efficiencies increased slightly with time. When the electrolysis time was increased to $90 \mathrm{~min}$, the reduction efficiency reached $2.92 \operatorname{logs}$ for sull, $2.84 \operatorname{logs}$ for sul2, $3.23 \operatorname{logs}$ for tet $M, 2.35 \operatorname{logs}$ for tet $W$, and $2.72 \operatorname{logs}$ for $16 \mathrm{~S}$ rRNA, respectively. The removal efficiency of EC for intracellular ARGs and extracellular ARGs with 60 min of electrolysis is shown in Table 3 and was in the range of 2.21$2.83 \operatorname{logs}$ and $1.82-2.56 \operatorname{logs}$, respectively.

$\mathrm{Fe}^{2+}$ is released at the anode, and $\mathrm{OH}^{-}$is formed at the cathode in the EC process when iron is used as the anode at neutral $\mathrm{pH}$. $\mathrm{Fe}^{2+}$ is further transformed into $\mathrm{Fe}(\mathrm{OH})_{2}$ or $\mathrm{Fe}(\mathrm{OH})_{3}$ when oxygen is present. These hydroxides neutralize charges and foster charge aggregation or act as sweep flocs with large surface areas that adsorb bacterial cells and dissolved pollutants (Ghernaout, 2013). Thus, the primary mechanism for the removal of ARGs and 16S rRNA genes in wastewater by EC might be the adsorption and enmeshment of precipitated flocs. In addition, the formation of permanent pores in the cell membrane or the loss of important cell components caused by the electric field may also lead to the activation of bacteria (Drees et al., 2003). To explore the potential mechanism of the removal of ARGs by EC, a correlation analysis was carried out between the removal efficiency for ARGs and that for $16 \mathrm{~S}$ rRNA with different electrolysis times. The abundance of 16S rRNA genes is often used to reflect the abundance of background bacteria in water samples (Ju et al., 2014). As shown in Table 4, the removal efficiencies for selected ARGs (sul1, sul2, tetM, and tetW) were all significantly correlated with that for $16 \mathrm{~S}$ rRNA, suggesting that the removal of ARGs during the EC process was mainly attributed to the removal of bacterial cells.

As shown in Fig. 1, both the selected ARGs and bacteria (16S rRNA) seemed to be removed effectively by the EC process. Although UV irradiation and chlorination have been widely used to inactivate bacteria in wastewater, their ability to remove ARGs is often limited, for example, only $0.80-$ $1.21 \operatorname{logs}$ by UV irradiation and 1.65-2.28 logs by chlorination (Zhang et al., 2016). As water quality may have important effects on the inactivation of bacteria and the removal of ARGs, a comparative study of EC and conventional disinfection processes using the same wastewater samples is necessary in the future.

Table 2. The Abundance of Selected Antibiotic Resistance Genes and 16S rRnA IN THE UNTREATED WASTEWATER (COPIES/ML)

\begin{tabular}{|c|c|c|c|c|c|c|c|c|}
\hline \multicolumn{4}{|c|}{ Intracellular ARGs } & \multicolumn{4}{|c|}{ Extracellular ARGs } & \multirow[b]{2}{*}{$16 S r R N A$} \\
\hline sul1 & sul2 & tetM & tetW & sul1 & sul2 & tetM & tetW & \\
\hline $6.31 \mathrm{E} 10$ & $1.26 \mathrm{E} 10$ & $1.58 \mathrm{E} 9$ & $3.16 \mathrm{E} 8$ & $2.51 \mathrm{E} 8$ & $3.98 \mathrm{E} 7$ & 5.01E6 & 2.37E6 & $3.82 \mathrm{E} 11$ \\
\hline
\end{tabular}

ARG, antibiotic resistance gene. 


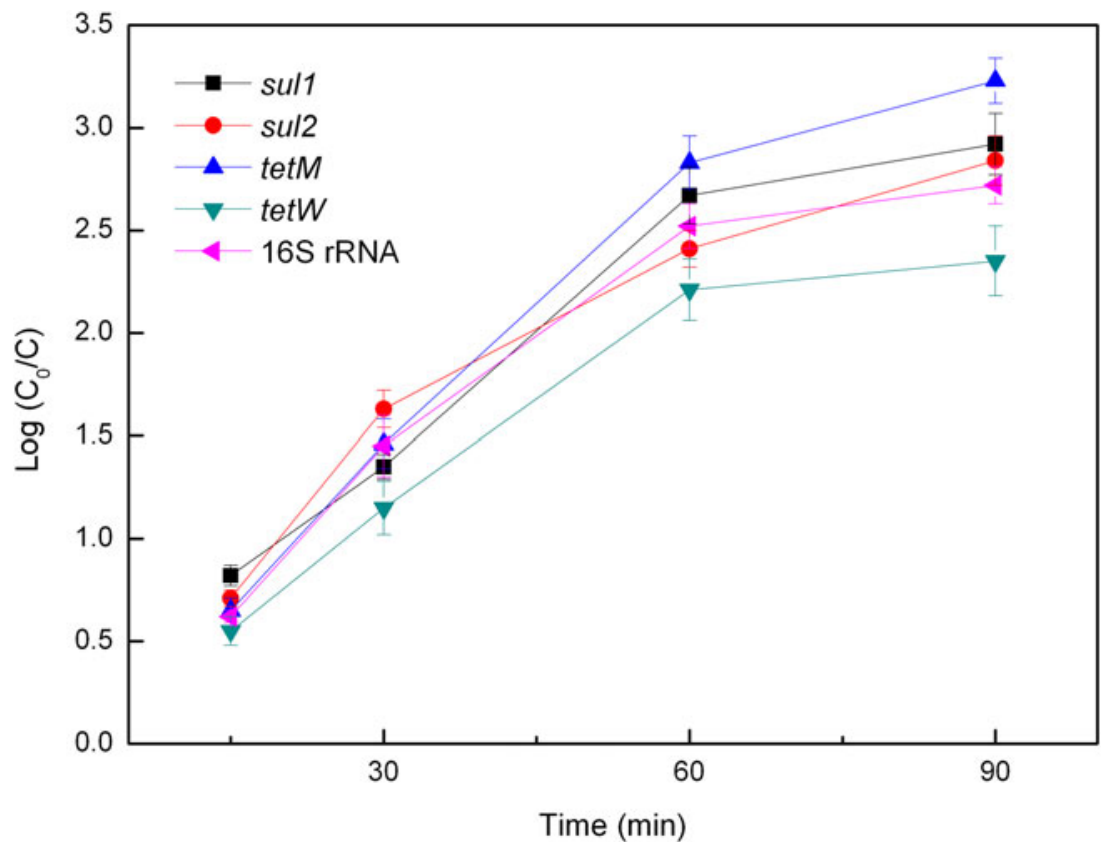

FIG. 1. Removal efficiencies of selected ARGs and 16S rRNA from swine wastewater by the electrocoagulation process. ARG, antibiotic resistance gene.

\section{EF process}

In the EF process, the reduction of ARGs and 16S rRNA genes increased slowly during the initial $15 \mathrm{~min}$ and then increased dramatically, which was quite different from the trend in the EC process, as shown in Fig. 2. This lag phase might be due to the protection of the cell wall and the defense of antioxidative enzymes against oxidative stress (Sun et al., 2016). After $90 \mathrm{~min}$ of electrolysis, the removal efficiency reached $1.92 \operatorname{logs}$ for sul1, $1.74 \operatorname{logs}$ for sul2, $2.63 \operatorname{logs}$ for tet $M, 2.35 \operatorname{logs}$ for tet $W$, and $1.82 \operatorname{logs}$ for $16 \mathrm{~S}$ rRNA, which was lower than that in the EC process. In addition, the reduction in sulfamethoxazole resistance genes (sull and sul2) was lower than that in tetracycline resistance genes (tet $M$ and $t e t W$ ), indicating that sulfamethoxazole-resistant bacteria had greater tolerance to oxidative stress than tetracyclineresistant bacteria. Similar findings were observed during chlorination and UV disinfection (Zhang et al., 2015b; Zheng et al., 2017). The removal efficiency of EF for intracellular ARGs and extracellular ARGs with 60 min of electrolysis is shown in Table 3 and was in the range of 1.03-2.19 logs and 3.19-4.02 logs, respectively.
During the EF process, hydrogen peroxide is generated in situ through oxygen reduction on the cathode. Then, hydrogen peroxide reacts with a small amount of catalytic $\mathrm{Fe}^{2+}$ to produce the hydroxyl radical $\bullet \mathrm{OH}$, which is well known as Fenton's reaction (Bruguera-Casamada et al., 2017). The strong oxidizing agent $\bullet \mathrm{OH}$ can react with the organic components of bacterial cells, destroy the cell structure, and then penetrate into the cells, oxidizing intracellular DNA molecules. Meanwhile, $\bullet \mathrm{OH}$ can directly oxidize free extracellular DNA molecules. In addition, the electric field applied may result in the formation of permanent pores in the cell membrane, allowing $\bullet \mathrm{OH}$ to freely enter the cell and enhancing the removal of ARGs (Drees et al., 2003). A correlation analysis between the removal efficiency for ARGs and that for 16S rRNA with different electrolysis times was also performed. As shown in Table 4, the removal efficiency for ARGs except tet $M$ was not correlated with that for $16 \mathrm{~S}$ rRNA, indicating that the decrease in the abundance of bacteria was not the reason for the removal of ARGs by the EF process, unlike in the EC process. The hydroxyl radical -OH is likely primarily responsible for the removal of ARGs during the EF process at $\mathrm{pH} 3.5$ in the present study. The

Table 3. Removal of Intracellular and Extracellular Antibiotic Resistance Genes By DifFerent TREATMENTS (LOG Copies/ML)

\begin{tabular}{|c|c|c|c|c|c|c|c|c|}
\hline \multirow[b]{2}{*}{ Treatment } & \multicolumn{4}{|c|}{ Intracellular ARGs } & \multicolumn{4}{|c|}{ Extracellular ARGs } \\
\hline & sul1 & sul2 & tetM & tetW & sul1 & sul2 & tetM & tetW \\
\hline $\mathrm{EC}^{\mathrm{a}}$ & 2.67 & 2.41 & 2.83 & 2.21 & 1.89 & 2.24 & 2.56 & 1.82 \\
\hline $\mathrm{EF}^{\mathrm{b}}$ & 1.21 & 1.03 & 2.19 & 1.75 & 3.82 & 3.53 & 4.02 & 3.19 \\
\hline Sequential EC/EF ${ }^{c}$ & 2.94 & 2.49 & 3.25 & 2.64 & 4.06 & 3.67 & 4.38 & 3.23 \\
\hline
\end{tabular}

${ }^{\mathrm{a}} \mathrm{EC}$ process $(60 \mathrm{~min})$.

${ }^{\mathrm{b}} \mathrm{EF}$ process $(60 \mathrm{~min})$.

${ }^{c} \mathrm{EC}$ process $(30 \mathrm{~min}) / \mathrm{EF}$ process $(30 \mathrm{~min})$.

$\mathrm{EC}$, electrocoagulation; EF, electro-Fenton. 
Table 4. Correlation Analysis Between THE Removal EFFiciencies of ANTIBIOTIC RESISTANCE GENES AND 16S RRNA

\begin{tabular}{lcccc}
\hline Process & sul1 & sul2 & tetM & tetW \\
\hline EC $\quad$ 16S rRNA & $0.958^{\mathrm{a}}$ & $0.991^{\mathrm{b}}$ & $0.974^{\mathrm{a}}$ & $0.976^{\mathrm{b}}$ \\
EF & & & & \\
$\quad$ 16S rRNA & 0.917 & 0.914 & $0.982^{\mathrm{a}}$ & 0.944
\end{tabular}

${ }^{\mathrm{a}}$ Correlation is significant at the 0.05 level (two tailed).

${ }^{\mathrm{b}}$ Correlation is significant at the 0.01 level (two tailed). initial $\mathrm{pH}$ has been reported to be the main factor that determines the efficiency of the Fenton process (Trapido et al., 2009). Fenton oxidation is often conducted within a $\mathrm{pH}$ range of 3.0-3.5; the yield of $\bullet \mathrm{OH}$ radicals is reduced due to the formation of $\mathrm{Fe}^{2+}$ complexes at a lower $\mathrm{pH}(<2.5)$ or due to the precipitation of ferric oxyhydroxides at a higher $\mathrm{pH}$ (>4.0) (Gogate and Pandit, 2004). The efficiency of Fenton oxidation is typically lower in neutral solutions than in acidic solutions.

Table 3 shows that EC was more effective for the inactivation of intracellular ARGs and bacterial cells, while EF had a greater ability to remove extracellular ARGs. This result might be due to the differences in the removal mechanisms of
FIG. 2. Removal efficiencies of selected ARGs and 16S rRNA from swine wastewater by the electro-Fenton process.

FIG. 3. Removal efficiencies of selected ARGs and 16S rRNA from swine wastewater by the sequential electrocoagulation/electro-Fenton processes.
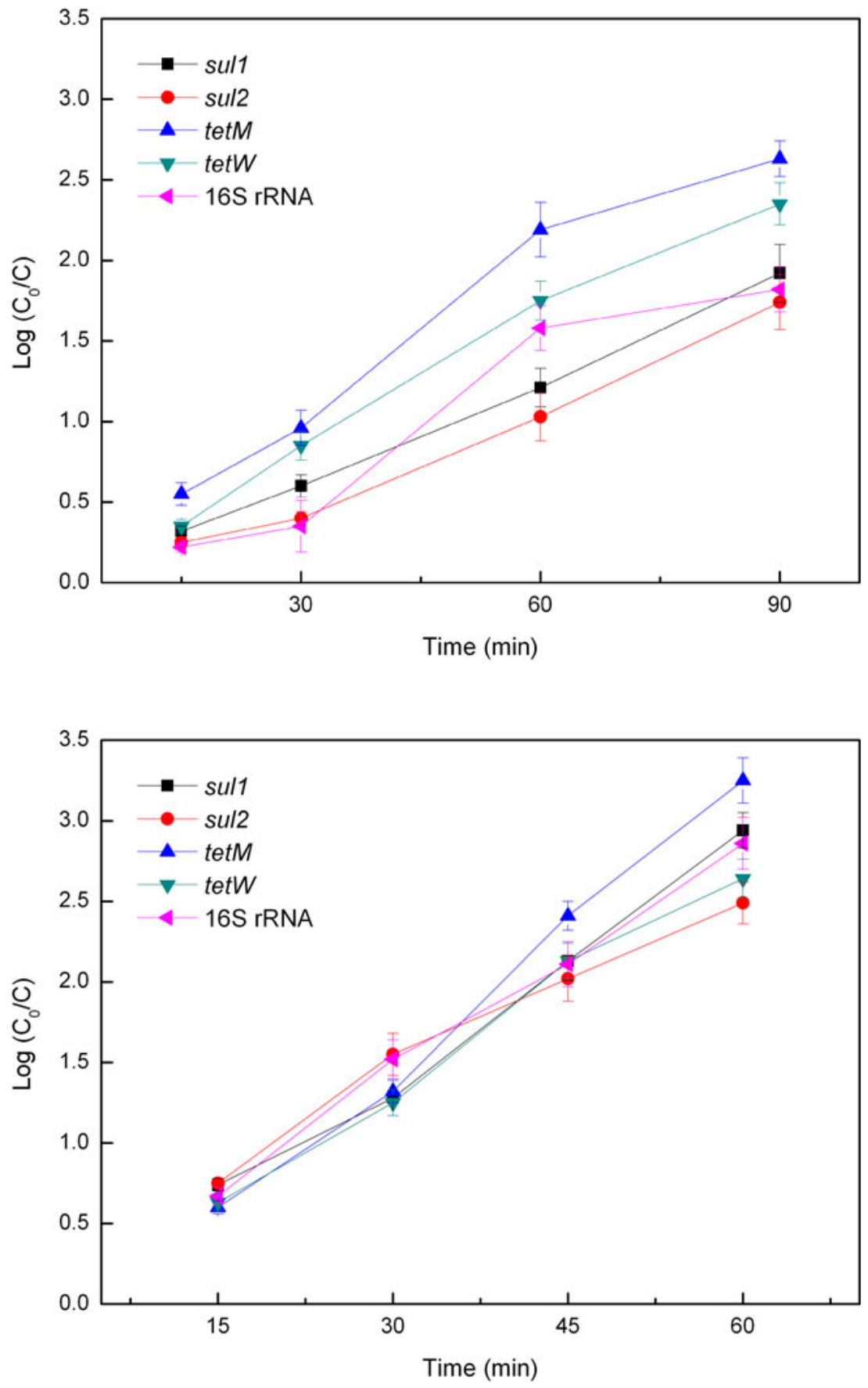
the two processes. Thus, sequential EC/EF processes were evaluated for their removal of both intracellular and extracellular ARGs.

\section{Sequential EC/EF processes}

The reduction in ARGs and 16S rRNA genes during the sequential EC/EF processes was similar to that during the individual EC process in the first $30 \mathrm{~min}$ but promoted by the EF process in the subsequent $30 \mathrm{~min}$ (Fig. 3). After $60 \mathrm{~min}$ of treatment, the removal efficiency for selected ARGs reached $2.94 \operatorname{logs}$ for sul1, $2.49 \operatorname{logs}$ for $s u l 2,3.25 \log$ s for tetM, $2.64 \operatorname{logs}$ for tet $W$, and $2.86 \operatorname{logs}$ for $16 \mathrm{~S}$ rRNA. The removal efficiencies for intracellular ARGs and extracellular ARGs are shown in Table 3, which were both higher than those by the individual EC or EF process alone. Pretreatment with the EC process seems to enhance the effect of the EF process. This may be because most of the bacterial cells were first removed by the adsorption and enmeshment of precipitated flocs during the EC process, and the resultant low bacterial density was beneficial for the action of $\bullet \mathrm{OH}$ radicals for the removal of ARGs in the subsequent EF process. In addition, the bacterial cell walls and membranes may have been weakened by their interaction with the hydroxide flocs in the EC process, which would promote the oxidant attack on ARGs in the subsequent EF process (Anfruns-Estrada et al., 2017). Compared to EC or EF alone, sequential EC/EF processes were more effective in the removal of both intracellular and extracellular ARGs.

\section{Conclusions}

Both EC and EF processes removed selected ARGs and $16 \mathrm{~S}$ rRNA from actual swine wastewater treatment plant effluent more effectively than conventional disinfection processes. As different mechanisms were involved in the two processes, EC was found to be superior for inactivating intracellular ARGs and bacteria, while EF was more efficient at removing extracellular ARGs. Sequential EC/EF processes were more efficient for the removal of both intracellular and extracellular ARGs than individual EC or EF processes; the removal efficiencies of the sequential process were 2.49-3.25 logs for intracellular ARGs and 3.23-4.38 logs for extracellular ARGs, respectively. The results suggest that the sequential EC/EF treatment is a promising method for the removal of both intracellular and extracellular ARGs from swine wastewater treatment effluent.

\section{Author Disclosure Statement}

No competing financial interests exist.

\section{Funding Information}

This work was supported by the Key Laboratory of Water Pollution Control and Environmental Safety of Zhejiang Province, China (No. 2018ZJSHKF04) and the Jiangsu Provincial Key Laboratory of Environmental Science and Engineering (No. Zd1904).

\section{References}

Anfruns-Estrada, E., Bruguera-Casamada, C., Salvadó, H., Brillas, E., Sirés, I., and Araujo, R.M. (2017). Inactivation of microbiota from urban wastewater by single and sequential electrocoagulation and electro-Fenton treatments. Water Res. $126,450$.

Auguet, O., Pijuan, M., Borrego, C.M., Rodriguez-Mozaz, S., Triadó-Margarit, X., Giustina, S.V.D., and Gutierrez, O. (2017). Sewers as potential reservoirs of antibiotic resistance. Sci. Total Environ. 605, 1047.

Baran, W., Adamek, E., Jajko, M., and Sobczak, A. (2018). Removal of veterinary antibiotics from wastewater by electrocoagulation. Chemosphere 194, 381.

Berendonk, T., Manaia, C.M., Merlin, C., Fatta-Kassinos, D., Cytryn, E., Walsh, F., Bürgmann, H., Sørum, H., Norstr€om, M., Pons, M.N., Kreuzinger, N., Huovinen, P., Stefani, S., Schwartz, T., Kisand, V., Baquero, F., and Martinez, J.L. (2015). Tackling antibiotic resistance: The environmental framework. Nat. Rev. Microbiol. 13, 310.

Bruguera-Casamada, C., Sirés, I., Brillas, E., and Araujo, R.M. (2017). Effect of electrogenerated hydroxyl radicals, active chlorine and organic matter on the electrochemical inactivation of pseudomonas aeruginosa using BDD and dimensionally stable anodes. Sep. Purif. Technol. 178, 224.

Dong, P., Wang, H., Fang, T., Wang, Y., and Ye, Q. (2019). Assessment of extracellular antibiotic resistance genes (eARGs) in typical environmental samples and the transforming ability of eARG. Environ. Int. 125, 90.

Drees, K.P., Abbaszadegan, M., and Maier, R.M. (2003). Comparative electrochemical inactivation of bacteria and bacteriophage. Water Res. 37, 2291.

Ghernaout, D. (2013). Advanced oxidation phenomena in electrocoagulation process: A myth or a reality? Desalination Water Treat. 51, 7536.

Gogate, P.R., and Pandit, A.B. (2004). A review of imperative technologies for wastewater treatment II: Hybrid methods. Adv. Environ. Res. 8, 553.

Goff, D.A., and Rybak, M.J. (2015). Global antimicrobial stewardship: Challenges and successes from frontline stewards. Infect. Dis. Ther. 4, 1.

Guo, C., Wang, K., Hou, S., Wan, L., Lv, J., Zhang, Y., Qu, X., Chen, S., and $\mathrm{Xu}$, J. (2017). $\mathrm{H}_{2} \mathrm{O}_{2}$ and/or $\mathrm{TiO}_{2}$ photocatalysis under UV irradiation for the removal of antibiotic resistant bacteria and their antibiotic resistance genes. J. Hazard. Mater. 323, 710.

Guo, M., Yuan, Q., and Yang, J. (2015). Distinguishing effects of ultraviolet exposure and chlorination on the horizontal transfer of antibiotic resistance genes in municipal wastewater. Environ. Sci. Technol. 49, 5771.

Jia, S., Zhang, X.X., Miao, Y., Zhao, Y., Ye, L., Li, B., and Zhang, T. (2017). Fate of antibiotic resistance genes and their associations with bacterial community in livestock breeding wastewater and its receiving river water. Water Res. 124, 259.

Ju, F., Xia, Y., Gu, F., Wang, Z.P., and Zhang, T. (2014). Taxonomic relatedness shapes bacterial assembly in activated sludge of globally distributed wastewater treatment plants. Environ. Microbiol. 16, 2421.

Li, N., Sheng, G.P., Lu, Y.Z., Zeng, R.J., and Yu, H.Q. (2017). Removal of antibiotic resistance genes from wastewater treatment plant effluent by coagulation. Water Res. 111, 204.

Oh, J., Medriano, C.A., and Kim, S. (2016). The effect of tetracycline in the antibiotic resistance gene transfer before and after ozone disinfection. Desalination Water Treat. 57, 646.

Rahmani, A.R., Samarghandi, M.R., Nematollahi, D., and Zamani, F. (2019). A comprehensive study of electrochemical 
disinfection of water using direct and indirect oxidation processes. J. Environ. Chem. Eng. 7, 102785.

Sharma, V.K., Johnson, N., Cizmas, L., Mcdonald, T.J., and Kim, H. (2016). A review of the influence of treatment strategies on antibiotic resistant bacteria and antibiotic resistance genes. Chemosphere 150, 702.

Sui, Q., Jang, C., Zhang, J., Yu, D., Chen, M., Wang, Y., and Wei, Y. (2018). Does the biological treatment or membrane separation reduce the antibiotic resistance genes from swine wastewater through a sequencing-batch membrane bioreactor treatment process. Environ. Int. 118, 274.

Sun, H., Li, G., An, T., Zhao, H., and Wong, P.K. (2016). Unveiling the photoelectrocatalytic inactivation mechanism of Escherichia coli: Convincing evidence from responses of parent andanti-oxidation single gene knockout mutants. Water Res. 88, 135.

Trapido, M., Kulik, N., Goi, A., Veressinina, Y., and Munter, R. (2009). Fenton treatment efficacy for the purification of different kinds of wastewater. Water Sci. Technol. 60, 1795.

Valero, P., Verbel, M., Silva-Agredo, J., Mosteo, R., Ormad, M.P., and Torres-Palma, R.A. (2017). Electrochemical advanced oxidation processes for Staphylococcus aureus disinfection in municipal WWTP effluents. J. Environ. Manage. 198, 256.
Zhang, Q.Q., Ying, G.G., Pan, C.G., Liu, Y.S., and Zhao, J.L. (2015a). Comprehensive evaluation of antibiotics emission and fate in the river basins of china: Source analysis, multimedia modeling, and linkage to bacterial resistance. Environ. Sci. Technol. 49, 6772.

Zhang, Y., Li, A., Dai, T., Li, F., Xie, H., Chen, L., and Wen, D. (2018). Cell-free DNA: A neglected source for antibiotic resistance genes spreading from WWTPs. Environ. Sci. Technol. 52, 248.

Zhang, Y., Yao, Z., Geng, J., Ren, H., Xu, K., and Ding, L. (2016). Reduction of antibiotic resistance genes in municipal wastewater effluent by advanced oxidation processes. Sci. Total Environ. 50, 184.

Zhang, Y., Zhuang, Y., Geng, J., Ren, H., Zhang, Y., Ding, L., and $\mathrm{Xu}, \mathrm{K}$. (2015b). Inactivation of antibiotic resistance genes in municipal wastewater effluent by chlorination and sequential UV/chlorination disinfection. Sci. Total Environ. $512,125$.

Zheng, J., Su, C., Zhou, J., Xu, K., Qian, Y., and Chen, H. (2017). Effects and mechanisms of ultraviolet, chlorination, and ozone disinfection on antibiotic resistance genes in secondary effluents of municipal wastewater treatment plants. Chem. Eng. J. 317, 309. 